some $\mathrm{f200m}$ (US $\$ 287 \mathrm{~m}$ ) short, and has announced it may cap large increases. And some have questioned the value of running the assessment again now that standards have leveled so substantially.

Compared with other subjects, CLS saw one of the sharpest increases in scores between 1996 and 2001, though not all rises may be entirely due to improving quality. Peter Cotgreave, director of the pressure group Save British Science, says that many universities have learned how to play the RAE system, for example by discouraging researchers from writing books, which are not included in the assessment and warns, "We're in danger of losing the distinction between accountability and control," referring to the fact that the RAE could be making universities direct their research programs towards areas in which they believe they will score most highly.

According to Martin Bobrow, head of the department of medical genetics at Cambridge University who chaired the CLS panel, "One of the reasons for the improvement in scores is that there has been an awful lot of restructuring, particularly in London." For example, Kings College London saw its rating soar from 2 to 5 , partly because this time around it was able to enter researchers from the United Medical and Dental Schools, with which it merged in 1998. Likewise, Imperial College can also thank researchers from several London hospitals recently taken under its wing for their contribution to its new $5^{*}$ status, up from 4 last time round. "In 1991 most submissions into CLS would have been in the traditional laboratory divisions of medicine," says Bobrow. "This time the submissions were more theme-focused and this has made for a much greater production of higher quality research and better quality research plans."

But officials insist that the upgrades are genuine. "The improvements in performance since the last RAE are a direct result of institutions managing their research strategically," says Howard Newby, chief executive of the Higher Education Funding Council for Engl and. Newby adds that some 300 international experts confirmed the world-class reputation of departments given the top grades, and that publication and citation counts also endorse the quality of UK research.

David Adam, London

\title{
Edible vaccines: not quite ready for prime time
}

After completing the first human trial to test the safety and immunogenicity of a potato-based vaccine for hepatitis $B$, researchers are facing up to therapeutic realities and shifting their strategy for future tests of 'edible vaccines'. "The original idea of eating something to get immunized was a naive view of how a medical product could be handled," says Charles Arntzen, founding director of the newly created Arizona Biomedical Institute and pioneer in edible vaccines.

When first proposed in the early 1990s, the idea of engineering tomatoes or bananas to express a vaccine and then feeding the fruits to vaccinees generated a lot of excitement, especially as an economical and convenient way to distribute vaccine to countries with less developed health infrastructures. But the practicalities of using edible material as medicines have since struck home. "We don't know the level of variability [in vaccine ex-

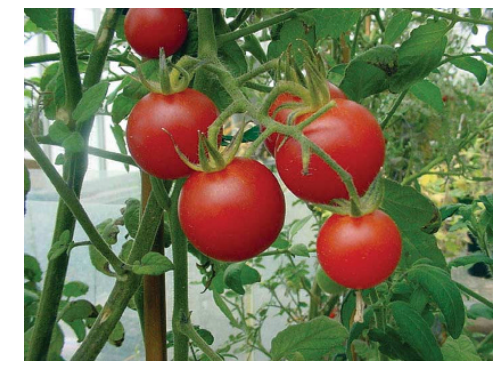

Tomato expressing RSV vaccine
B virus, which causes fatal liver disease. The intestinal immune system typically responds to antigens present in food by preventing the development of immune responses against them, thus enabling food to be eaten. Whether a limited number of vaccine doses delivered in the context of a food product would induce such tolerance is unknown.

Mason says that his group now plans to evaluate the plant-based hepatitis B vaccine in a lower primate model to determine the potential of oral tolerance. His group is also planning a human trial of a vaccine for a less dangerous virus, the Norwalk virus that leads only to a mild grastrointestinal infection, and for which Mason hopes the FDA will approve a study where immunized volunteers are then challenged with the virus. The group will test the vaccine in a dry tomato powder. The trial, if approved, would be the first test of efficacy of pression] from plant to plant or from field to field," says "It is difficult to beconfident about dose," says Hugh Mason, of the Boyce Thompson Institute for Plant Research at Cornell University who worked on the potato-based trial with Arntzen.

One possibility is freezedrying the products of transgenic plants. The resulting plant-based powders or pel lets can still bestored at room temperature - one of the most enticing features of edible vaccinesbut, unlike fresh produce, each pellet would contain a well-defined, consistent dose of vaccine. The added advantage of the freeze-drying process is that it concentrates the amount of protein expressed by the plant that generates the immune re sponse (the antigen), by 20-30-fold.

Only three Phase I/II trials of plantbased vaccines have been published to date and the end-point in each case has been antibody generation. For the potatobased hepatitis B trial, the Food and Drug Administration (FDA) would only permit the boosting of antibody levels in individuals already immunized with the injectable hepatitis $B$ vaccine, rather than naive subjects, because of safety concerns-most notably that vaccinees may develop immunetolerance to the hepatitis an edible vaccine against infection and the first of the new 'powder vaccines'.

The shift in thinking from whole-fruit or vegetable vaccines to dry powders will result in a more costly and complex production strategy than that initially envisioned, but Arntzen stresses that the technology continues to make use of the infrastructure for crop production, food processing, and storage that al ready exist in most countries.

Oral vaccines have the advantage of higher compliance and no risk of contamination from needles. For these reasons, philanthropic organizations with an interest in providing sustainableimmunization systems to the developing world have shown the most enthusiasm for the technology. "Certainly the appeal is still there," says M argaret Liu, senior advisor of vaccinology for the Bill \& Melinda Gates Foundation. But there are still many challenges. "I know of 20 groups working on the plant side but clinical groups are not interested," says Arntzen. And if clinical groups are showing little interest, big pharmaceutical companies will show even less. "The biggest challenge will be to get pharmaceutical companies to put money in it," says Mason.

\section{Laura Bonetta, Bethesda}

